\title{
The Application of Fine Three-Dimensional Structure Modeling in P2
} Block

\author{
Chenqiang Dong ${ }^{1, a}$, Xue $\mathrm{Li}^{2, \mathrm{~b}}$ \\ ${ }^{1}$ Xinchun Oil Recovery Plant, Shengli Oilfield, Dongying, 257001, China \\ ${ }^{2}$ College of Resources Science \& Technology, Beijing Normal University, Beijing 100875, China \\ adcq010@163.com, blix@mail.bnu.edu.cn
}

Keywords:P2 block; Three-dimensional structure modeling; Fault modeling, Surface modeling

\begin{abstract}
Reservoir modeling is a method of describing reservoir parameters' distribution law in space from three-dimensional point with computer technology, combined with seismology, geology, well logging and other information. Geological modeling, the new emerging technology, developed in the late 1980s. It has been a technology of quantitative visualization of fine reservoir modeling from the early simulation method after years of gradual geostatistics development. With the deepening of domestic and international oilfield exploration and development, the early simulation method can not meet the requirements of fine reservoir description. Therefore, the fine structure modeling emerged at this situation, in this paper, fine structure modeling is applied in P2 block and has achieved a good result, providing favorable guidance for the reservoir exploration and program adjustments.
\end{abstract}

\section{Introduction}

Chunguang Oilfield lies in the east part of Chepaizi uplift, which belongs to the West Junggar upthrust that is a single inclined structure to north uplist and often develops vertical faults inside the structure.The main formation of this research is Neogene Shawan Formation.The type of reservoir is shallow complex lithologic,which is of thick thickness, bad diagenesis and strong concealment, etc.

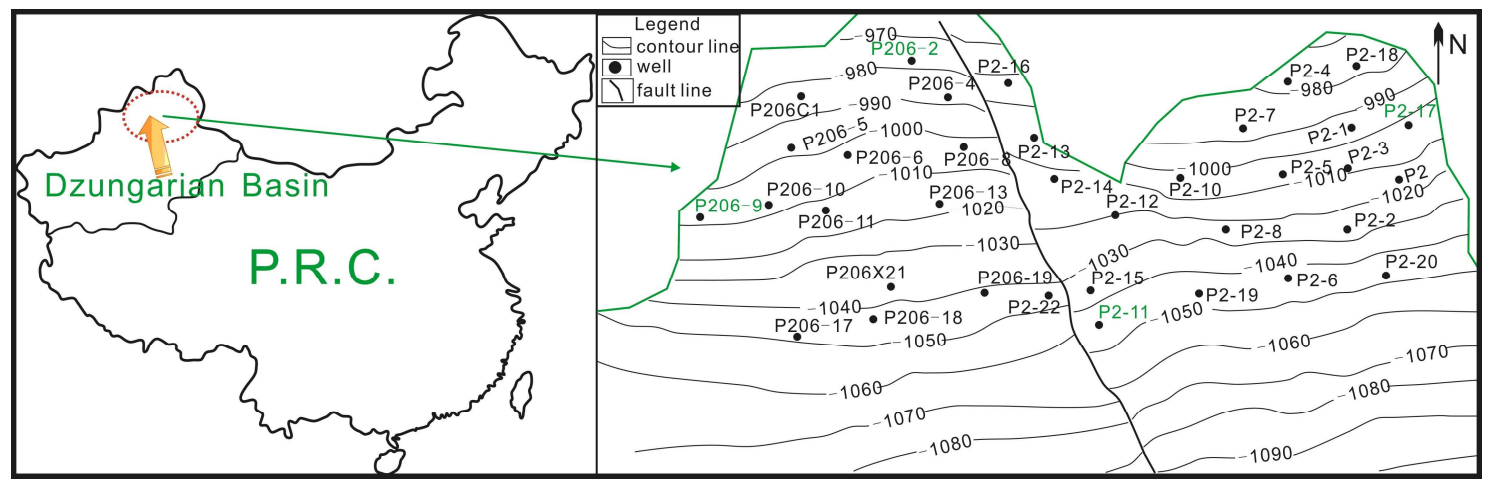

Fig.1 The location map of Chunguang Oilfield, showing the structure map of P2 block and the modeling boundary

P2 block is the main block of Chunguang oilfield, it locates on No.2 structure which belongs to Chepaizi salient in western uplift.The boundary of P2 block is P206-2 to the north, P2-11 to the south, P206-9 th the west and P2-17 to the east, shown in Fig.1. Fig.2 is the flow chart of the study with graphical description, showing the basic process of fine geological modeling. 


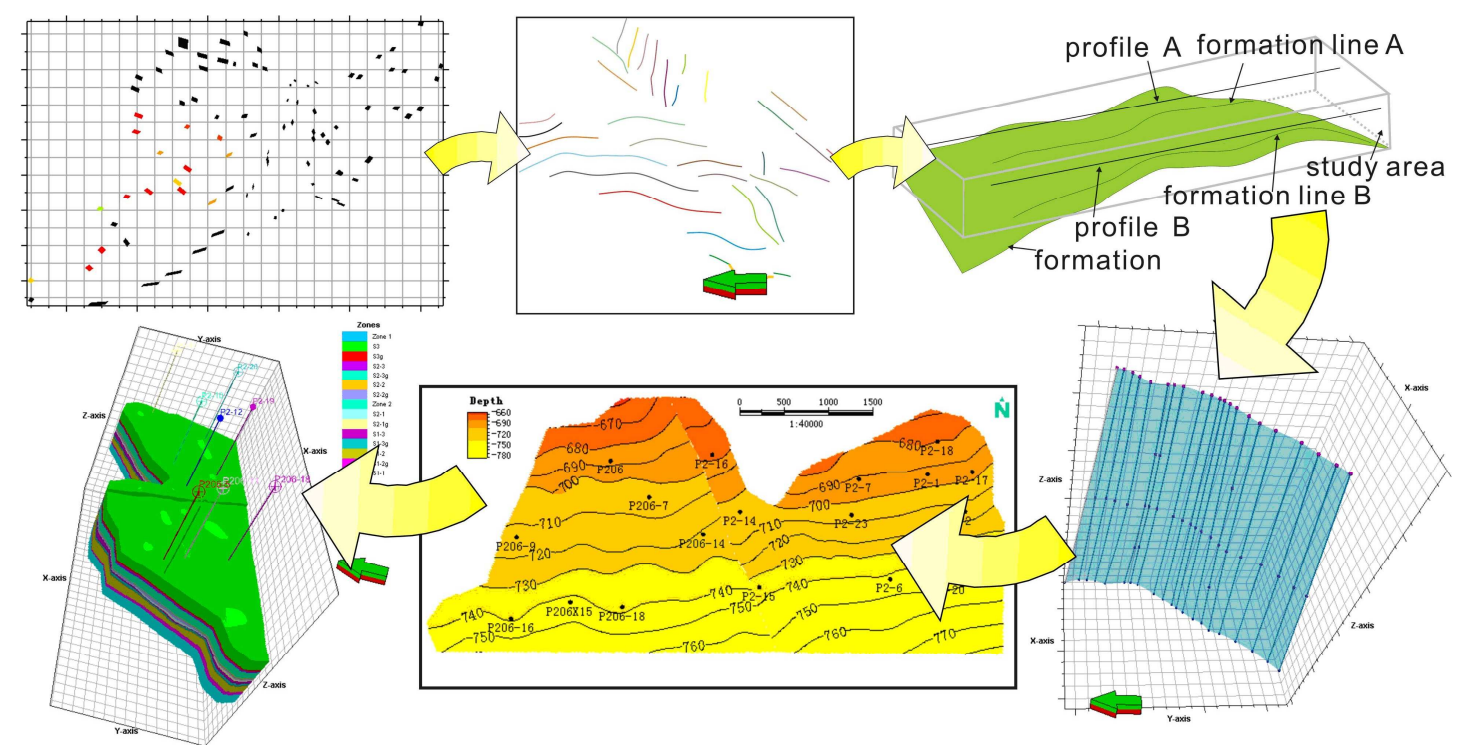

Fig.2 Flow chart of the study with graphical description, showing the basic process of fine geological modeling

\section{Structural trap characteristics}

The bedrock top surface of P2 block and overburden cap rock showns southeastern incline. The strata ups and downs of the area is gentle with the dip $2^{\circ}$; a series of approximate vertical positive fault, with the drop of $10-20 \mathrm{~m}$ and extension of $2-10 \mathrm{~km}$, developed under the regional transtensional stress. The large normal fault in North-West trend divide P2 block into the western part and eastern part.The fault breaking is small,so the reservoir is still keeping connective. The structural trap of the study area develops well,mainly including stratigraphic-structure trap, stratigraphic trap and fault trap. Among them, stratigraphic-structure trap is formed by fault development and formation overlayer. Stratigraphic trap is formed by valley infilling. Fault trap is formed by fault continous development. The cover of these traps is relatively larger and they are favorable for hydrocarbon accumulation.

\section{Structure modeling}

Structure modeling including fault model and surface model, is established with geological stratification and fault data.

Fault modeling. The fault model, the base of structure model, reflects the fault plane in the three-dimensional space. Only high quality fault model can built a good grid system to ensure the following modeling work efficiency. During the structure modeling of P2 block, the structural map is firstly imported and then the digital fault point data is obtained, which is used for fault plane.The fault plane is constantly adjusted in in order to ensure the accuracy of the fault model.There is only one fault developed in P2 block, it's tendency is south-west and the dip is $86^{\circ}$.Though the fault breaking is small,it covers all the layers, Fig. 3 is the three-dimensional section map of geological model along the parallel and the vertical direction of the fault extension. 


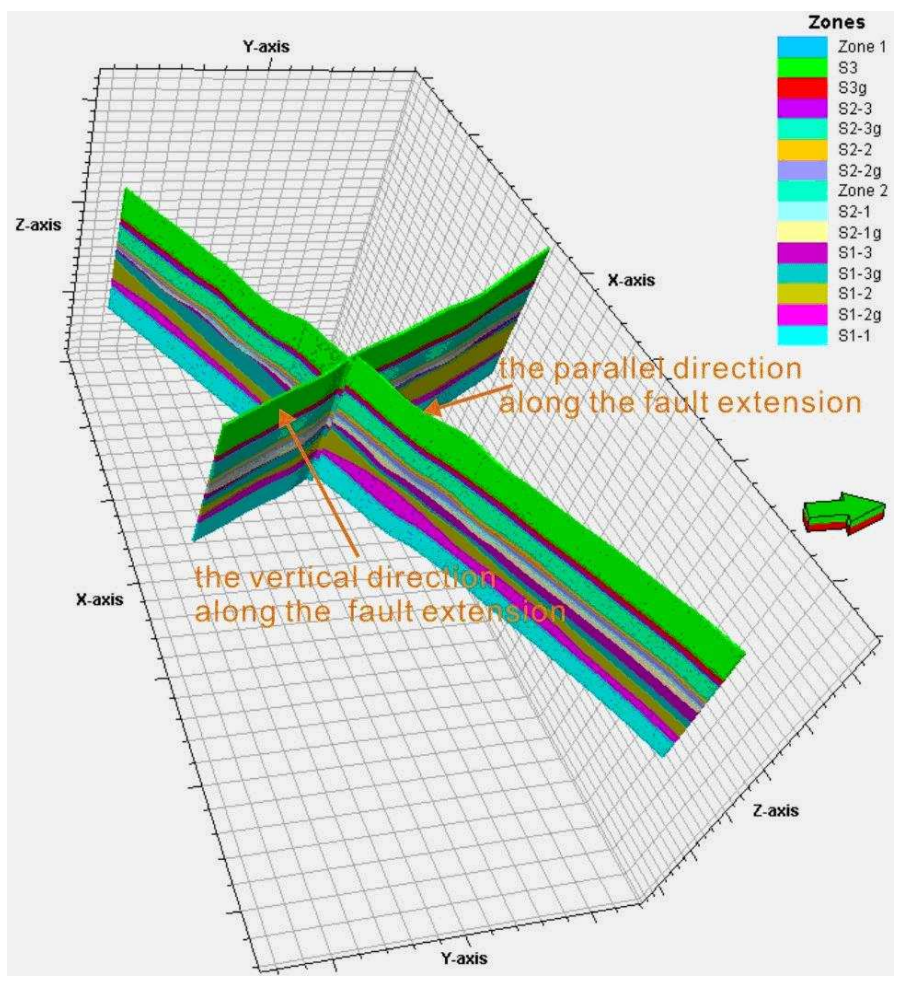

Fig.3 Three-dimensional section map of geological model along the parallel and the vertical direction of the fault extension

Surface modeling. Surface model reflects the ups and downs of stratigraphic surfaces in three-dimensional space. The stratigraphic framework model is formed by the overlayer of surface model. The methods of establishing stratigraphic framework model are mainly sliding average method and minimum curvature interpolation method.After the establishment of fault model and grid system,the surface model is established with minimum curvature interpolation method. It mainly consists of two steps.

\section{Surface establishment}

Due to larger numbers of sandbodies and interlayers, the surface is firstly established with the control of hierarchical data of two sand groups and then the surface is used as the constraint for other surfaces' establishment after fine adjustment. The unusual points on the surface are modified to make it consistent with actual geological information.

\section{Vertical division of grid system}

The vertical division of grid system includes Make Zones and Layering. During the process of Make Zones,the sand thickness data are directly insert into the surface which has been adjusted in order to prevent the level intersect.Fig.4 Fig.7 are the surface model and Fig.8 is the structure model and fence map of P2 block.Followed by surface modeling is Layering, the step is the further division of zones.In this paper,only the sandbody is divided with Layering according to the average thickness, except the interlayer. The grid system size of P2 block is $333 \times 220 \times 81$, with the three-dimensionalgrid number of 5934060 after further division.

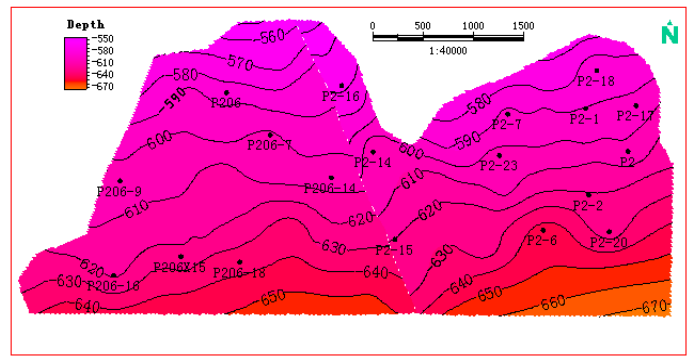

Fig.4 The surface model of $\mathrm{N}_{1} \mathrm{~S}_{3}$ of $\mathrm{P} 2$ block

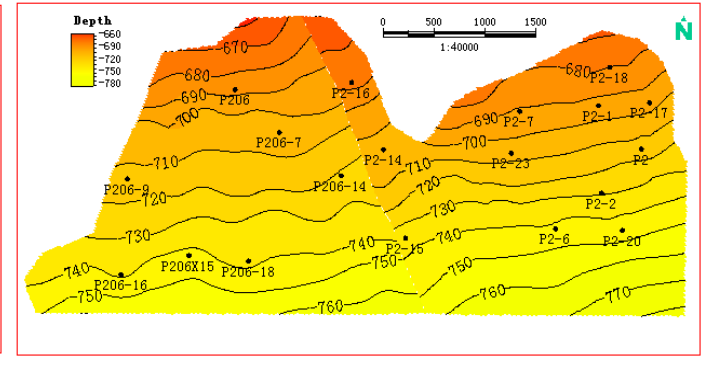

Fig. 5 The surface model of $\mathrm{N}_{1} \mathrm{~s}_{2}{ }^{1}$ of $\mathrm{P} 2$ block 

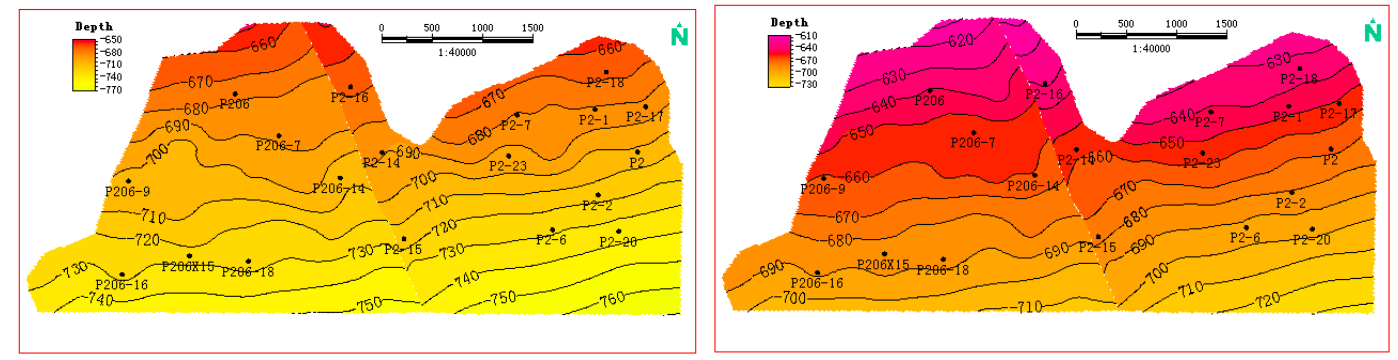

Fig. 6 The surface model of $\mathrm{N}_{1} \mathrm{~s}_{2}^{2}$ of P2 block Fig.7 The surface model of $\mathrm{N}_{1} \mathrm{~s}_{2}{ }^{3}$ of $\mathrm{P} 2$ block
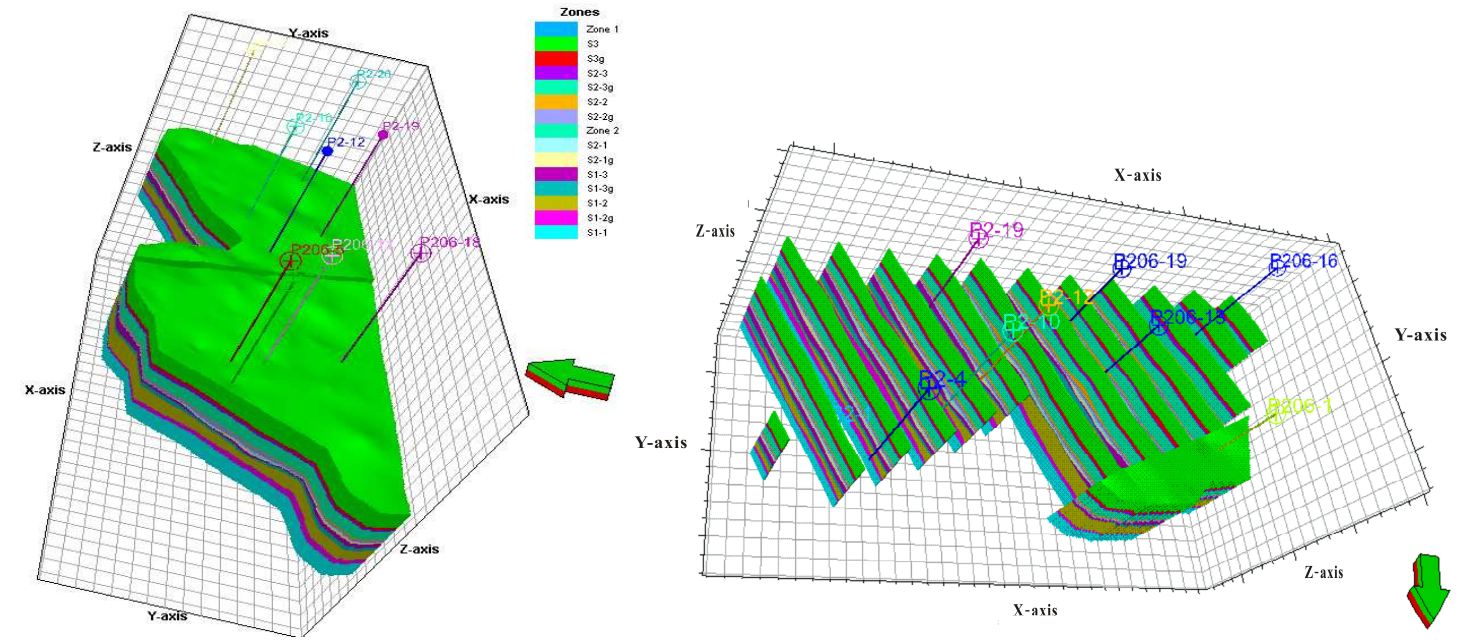

Fig. 8 The three-dimensional structural model and its fence map, reflecting the internal structure of P2 geological body

\section{Summary}

Fine three-dimensional structure modeling of P2 block is established on the basis of fine structural interpretation and geological stastics. With human interactive editing and three-dimensional visualization, the three-dimensional geological model which is consist with actual geological geological is built.

Three-dimensional geological modeling is a powerful tool for P2 reservoir development. Many problems resulted in traditional methods of geological research can be solved by establishing fine three-dimensional geological model.

\section{Acknowledgement}

The authors thank the workers of Beijing Normal University for supplying researching data and assistance.

\section{References}

[1] Zhang Jinliang, Ma Xueping, Zhang Zhongjie, Zhang Xin. The Importance of User Interaction In 3D Geological Modeling and Reservoir Exploitation. Proceeding of First International Conferenceon Modelling and Simulation. 2008, 290-293.

[2] Xue Li, Jinliang Zhang. "Applications of Three-Dimensional Geological Modeling in the Development of Da Qingzi Oilfield”. Second International Conference on Modeling, Simulation and Visualization Methods, 2010, ISBN: 978-0-7695-4046-7, pp.124-127.

[3] Haldorsen H H, Damsleth E. Stochastic modeling [J]. JPT, 1990, 42(4):404-412. 
[4] AI-Khalifa,M.H,(2001). Data Intergration in 3D Geostatistical Porosity Modeling of Hanifa Reservoir in Bsrri Field, Saudi Arabia, Master of Science Thesis,Department of Earth Science,KFUPM.

[5] Ma, Xueping, Zhang Jinliang “Application of artificial neural networks in lithofacies interpretation used for 3D geological modeling”. 2009 Second ISECS International Colloquium on Computing, Communication, Control, and Management, CCCM 2009, Vol. 4, pp. 451-454.

[6] AI-Salem,A.A.,(1996). Geostatistical Modeling of Arab-D Reservoir, Harmaliyah Field, Saudi Arabia, Master of Science Thesis, Department of Earth Sciences, KFUPM.

[7] JOURNEL A G. Geostatistics and reservoir geology[A]. In : Yarus and Chamber (eds.). Stochastic Modeling and geostatistics: Principles, Methods, and Case Studies[C]. AAPG Computer application in Geology, 1994,(3).

[8] Li, D., and Beckner, B., "A New Efficient Averaging Technique for Scaleup of Multimillion-Cell Geologic Models", SPE 56554, ATCE, Houston, Texas, 3-6 October, 1999.

[9] SRIVASTAVA R M. An overview of stochastic methods for reservoir characterization[A]. In: Yarus and chamber(eds.). Stochastic Modeling and Geostatistics: Principles, Methods, and Case Studies[C]. AAPG Computer.

[10]Liu, J.S., Willkins, J.R., Al-Qahtani, M.Y., and Al-Awami, A.A.,(2001). Modeling a Rich Gas Condensate Reservoir with Composition Grading and Faults, Society of Petroleum Engineers, SPE 68178, p 1-3. 